\title{
Perceived Family Interactions and Psychosocial Development of Family Members
}

\author{
Olga Poljšak Škraban \\ University of Ljubljana, Ljubljana, Slovenia
}

\begin{abstract}
In the article, the author summarizes the main findings of research aimed at examining the differences between the parents' and the adolescent daughters' perception of family interactions (relating to important qualities of parenting and the family competence) in the period of childhood and adolescence, as well as their connectedness to the psychosocial development of family members (especially adolescent daughters). The research is based on Beavers' (Beavers \& Hampson, 1993) systems model of family functioning and Erikson's (1980) theory of psychosocial development. The research included two-parent families of female adolescents. The main findings of the research are that daughters and their parents perceive the interactions in the family system differently. The daughters' evaluations were the lowest, i.e., the most critical. All family members experienced a drop in the quality of interaction during adolescence. In terms of perceiving family interaction, the families became clearly divided on the competence continuum into two groups. Correlations between the family's competence and the level of the adolescents' psychosocial development were significant, albeit not high, as were the correlations between the levels of psychosocial development of the parents and the adolescents.
\end{abstract}

Keywords: perceived family interactions, parenting, family competence, psychosocial development, late adolescence

\section{Introduction}

Adolescence is a period of development that is of key importance to the shaping of an individual's psychosocial and identity development. It is generally assumed that different social settings influence the identity formation process (Adams \& Marshall, 1996; Kroger, 2004). The family is probably one of the most significant social contexts for identity formation (Ule, 2008). Lewis (1989) asserted that a competent family is one that provides the adolescent with the optimal conditions for developing his/her identity. Studies on familial context clearly indicate how important family conflict and family interaction styles are for identity (Grotevant \& Cooper, 1985). The results of the Beyers and Goosens' (2008) study showed that parenting and identity formation are dynamically interlinked and underscore the fact that parents continue to be an important source of socialization for their developing children even in late adolescence. Gilligan (1982) purported that family relationships are particularly important to the development of adolescent females in that women are socialized and oriented toward emotional bonds, attachment and connectedness in their families. This is connected to the findings of those authors who view different types of interaction between the adolescent, the father and the mother as vital for successfully concluding the development of identity (Bartle-Haring, 1997; Cooper \& Grotevant, 1987).

In researching the family, we have drawn from Beavers' (1976) systems model of family functioning

Olga Poljšak Škraban, Ph.D., assistant professor, Faculty of Education, University of Ljubljana. 
(Beavers \& Hampson, 1993; 2000) and Lewis' (1989) theory. Beavers (Beavers \& Hampson, 1993; 2000) defined the family as an interactive unit. This systemic viewpoint for understanding the family is based on the premise that all family members contribute to the creation and maintenance of the system and that the individual functioning and development of family members are affected by the family system. The unit under observation in this case is the family as a system. According to Beavers (Beavers \& Hampson, 1993), the key dimensions defining the level of a family's functionality are competence and the style of interaction in the family. Family competence (Lewis, 1989) is defined as the extent to which a family accomplishes two cardinal tasks: (1) producing psychosocially healthy children who can function autonomously and enter into enduring relationships outside the family; and (2) stabilizing the parents' personalities while facilitating their continuing development. These two tasks are important throughout the entire life cycle of the family and, as such, can be considered as the basic perspective from which phase-specific family developmental tasks can be viewed. This is the basis for Beavers' (Beavers \& Hampson, 1993) further definitions of competence, where it is defined in connection to the capabilities of the family as an interactive unit, performing the necessary tasks of organizing and managing itself. The key elements of competence are: (1) the structure of the family unit-egalitarian leadership of the family, strong parental or other adult coalition and established generational boundaries; (2) the development of the autonomy of family members, evident in increasing trust, clear and distinct boundaries, clear and direct communication and the ability to deal with or accept differences; (3) the ability to resolve conflicts, skills of clear and direct communication; and (4) spontaneity, expressing a wide array of emotions and optimism. The style of interaction is a dimension Beavers (1976) based on Stierlin (1974; as cited in Beavers, 1976), and refers to centripetal (directed inwards) and centrifugal (directed outwards) tendencies concerning the effect on an adolescent's separation. In centripetal families, the parents bind the adolescents to themselves, and in centrifugal families, they encourage the separation of the adolescent. The family system functions in a healthy way when it is flexible. This means that a competent family alters its style according to its responsibilities and developmental needs throughout the family's life cycle.

The theoretical starting point for researching identity development was Erikson's (1968; 1980) concept of psychosocial development. Erikson $(1968 ; 1980)$ emphasized the development of individual characteristics in response to the demands of social interaction. The process of developing identity involves a linear process in which individuals develop ego "strengths" to successfully complete a developmental task (or stage) in order to move to the next task. Each of the eight developmental stages is characterized by a conflict, and each conflict contains the possibility of bipolar outcomes. Erikson $(1968 ; 1980)$ suggested that the individual must experience both sides of the conflict and must learn to subsume them into a higher synthesis. This bipolar nature of the social crisis gives each stage its name (trust vs. mistrust, autonomy vs. shame and doubt, initiative vs. guilt, industry vs. inferiority, identity vs. identity confusion, intimacy vs. isolation, generativity vs. stagnation and integrity vs. despair). If the conflict is worked out in a constructive, satisfactory manner, the positive quality becomes the dominant part of the ego and enhances further healthy development through the subsequent stages. If the conflict persists past its time, or is resolved unsatisfactorily, the negative quality is incorporated into the personality structure. Thus, movement from one stage to the next creates a change in our identity. The stages have a cumulative relationship with, or influence on, each subsequent stage (Bradley, 1985; Ochse \& Plug, 1986). Although identity crisis is most pronounced during adolescence, identity issues remain a lifelong concern. Erikson's (1980) theory dealt with development throughout an entire life span, and was, therefore, suitable for examining the psychosocial development in adolescents and their parents, as we were 
also interested in the role that the parents' psychosocial development plays in the identity development of the adolescents. Although it is true that Erikson's $(1968 ; 1980)$ constructs are difficult to define, there are some instruments that indicate their construct validity (Ochse \& Plug, 1986).

The research sheds light on the "inner life" of (one segment of Slovenian) families - It examines the psychological processes taking place in the family unit, using the method of self-reflection of its members, as defined by Čačinovič Vogrinčič (1998). Many family studies during adolescence have considered only as the adolescents' perceptions of the family system, although some studies have reported that adolescents' and parents' perceptions of family characteristics may be very different and may predict adolescent outcomes differently (Paulson \& Sputa, 1996). This is the reason why we are interested in the differences among the family members' perception of family interactions (relating to important qualities of parenting and family interactions and family competence) in the period of childhood and adolescence, as well as in their connectedness to the psychosocial development of the family members (especially adolescent daughters). Due to the fact that some authors have found significant gender-specific differences in the shaping of identity (Josselson, 1987; Marcia, 1993), the research focuses on a narrower field, researching the psychosocial development of adolescent females. Our expectations were the following that: (1) Differences in the perceptions of family members exist; (2) These differences increase in the period of adolescence; and (3) Family interaction, family competence and the parents' own psychosocial development are important factors for the psychosocial development of adolescents. This is consistent with the claims of other authors (Lewis, 1989; Ule, 2008).

\section{Method}

The basic principle of researching family system interactions is exploring the perceptions of all three family members, those of both parents and the daughter. This fact determines the techniques used for the data analysis. As proposed by Fisher, Kokes, Ransom, Phillips, and Rudd (1985), we analyzed data on an individual level (for each family member), on a dual level (comparative analysis of pairs) and on a systemic level (considering the family as a unit).

\section{Participants}

The sample was recruited among female students from the Faculty of Education in Ljubljana. There were 118 two-parent families invited to participate in the research, $85 \%$ of whom returned the testing material. In the end, $78 \%$ of the families returned testing material in which all of the data were provided and were thus included in the research. The research included 92 female students (20-25 years old, $M=21.6)$ and both of their parents (35-65 years old, $M=48.9$ ). The sample is comparable to the demographic structure of the population in terms of the students' residence and the population of students' parents in terms of the educational structure of the parents.

\section{Measures}

The instruments used in the research are based on the theoretical foundations presented in the introduction. All of the instruments were investigated according to psychometric characteristics. With the help of a modified "Family of Origin Questionnaire" Lewis (1989; base on Shereshefsky \& Yarrow (1973) and the Beavers (1976) Interactional Competence Scale), we examined two issues: (1) family interaction, relating to important qualities of parenting; and (2) family interaction, relating to the family as a system (family competence) and the way all three family members experience these two issues. Each of the 22 items in the entire questionnaire is rated in a 
five-point scale, with the extreme and the central points anchored by wordings tailored to the item content. For example, how close was your mother to you when you were a child? (1) "Distant", (3) "Close" and (5) "Very close". The structure of the questionnaire after component analysis (using principal component analysis; varimax rotation), which served as the basis for further research (more as cited in Poljšak Škraban, 2002a), was as follows. In the first part of the questionnaire, where the family members answered questions about important qualities of parenting, we analysed six variables referring to childhood and six variables (of the same content) referring to the adolescence of the daughter. Each question was individually designed for researching the relationship between the daughter and both parents. The extracted components are: (1) parents' anxiety about parenting; (2) dealing with needs (which included the following items: the parents' sensitivity to the daughter's feelings and needs; the parents' support of the daughter's feelings and needs; closeness between the parents and the daughter; the parents' happiness with the parental role); and (3) parents' intrusiveness. The second part of the questionnaire concerns experiencing the family as a system (family competence). The extracted components are: (1) structure of the family (which included: decision-making and the parental coalition); (2) communication (including: negotiation; communication; conflicts; connection to surroundings); and (3) dealing with emotions (including: permeability; expressiveness; mood and tone; empathy). The results of the component analysis and the internal reliability coefficients (Cronbach alpha in the composite scales ranges from 0.67 to 0.90 ) illustrate the satisfactory psychometric characteristics of the instrument.

For measuring psychosocial development, we used two questionnaires based on Erikson's $(1968 ; 1980)$ theory. "Wessman and Ricks' Questionnaire" (1966; as cited in Lamovec, 1994) is appropriate for measuring the adolescent's psychosocial development. The questionnaire contained 60 items, referring to the first six of Erikson's (1980) stages. Each item is rated in a 7-point Likert scale, from one ("I don't agree") to seven ("I agree"). According to the scale validation of the Slovene version (Poljšak Škraban, 2002a) which was similar to Ochse and Plugs' (1986), we calculated the sum score across all subscales (trust, autonomy, initiative, industry, identity and intimacy), reflecting the global degree of psychosocial development. The scale reliability (Cronbach alpha) is 0.88 (0.57-0.80 for the six subscales). "Ochse and Plugs' Questionnaire" (1986; as cited in Lamovec, 1994) is a suitable tool for measuring parents' psychosocial development. The questionnaire contained the first seven of Erikson's subscales (93 items). Each item is rated in a 4-point Likert scale from 1 ("Never") to 4 ("Very frequently"). As in the previous scale, the sum score across all subscales (trust, autonomy, initiative, industry, identity, intimacy and generativity) reflects the global degree of psychosocial development in parents. The scale reliability (Cronbach alpha) is 0.92 (0.65-0.83 for the seven subscales).

\section{Data Collection and Processing Procedure}

The data were collected in two ways: Students provided data in group settings at the faculty and parents provided data individually at home. The research material was sent to each parent separately by mail and was also returned in this way.

The statistical procedures for each particular section of the research are described simultaneously in the results section below.

\section{Results}

The presentation of the results is subdivided into two sections. First, we review the perceptions of the family interactions on a dual level (comparative analysis of pairs) and a systemic level (the family as a unit). 
Then, we examine the connectedness between family competence and the family members' (especially the adolescents') psychosocial development.

\section{Analysis of the Perceptions of Family Interactions}

The analysis of the perceptions of family interactions among the family members relating to important qualities of parenting takes into account individual and composite variables of Part 1 of the "Family of Origin Questionnaire" (qualities of parenting). The differences in the perceptions were examined using a comparative analysis of the perceptions of pairs-mother-daughter and father-daughter-using the independent samples $t$-test and, in the case of the analysis of the differences between childhood and adolescence, the one sample $t$-test. The Levene statistic for testing the homogeneity of variances was considered in advance. Both results are presented in Table 1.

Table 1

Differences Among the Family Members According to Experiencing the Qualities of Parenting in Childhood and Adolescence

\begin{tabular}{|c|c|c|c|c|c|c|c|c|c|c|}
\hline \multirow[t]{3}{*}{ Qualities of parenting } & \multicolumn{5}{|c|}{ Mother } & \multicolumn{5}{|c|}{ Father } \\
\hline & \multicolumn{2}{|c|}{ Adolescent perceived } & \multicolumn{3}{|c|}{ Mother perceived } & \multicolumn{2}{|c|}{ Adolescent perceived } & \multicolumn{3}{|c|}{ Father perceived } \\
\hline & $M$ & $S D$ & $M$ & $S D$ & $t(d f)$ & $M$ & $S D$ & $M$ & $S D$ & $t(d f)$ \\
\hline \multicolumn{11}{|c|}{ 1. Parents' anxiety about parenting } \\
\hline Childhood & 2.65 & 0.94 & 2.42 & 1.00 & $1.58(184)$ & 3.18 & 1.07 & 3.80 & 0.90 & $0.74(178)$ \\
\hline Adolescence & 2.66 & 0.90 & 2.48 & 0.98 & $1.24(184)$ & 3.09 & 0.99 & 2.96 & 0.97 & $0.90(184)$ \\
\hline $\begin{array}{c}\text { Childhood-adolescence } \\
t(d f)\end{array}$ & \multicolumn{2}{|c|}{$-0.12(92)$} & \multicolumn{3}{|c|}{$-0.83(92)$} & \multicolumn{2}{|c|}{$1.04(92)$} & \multicolumn{3}{|c|}{$1.55(92)$} \\
\hline \multicolumn{11}{|c|}{$\begin{array}{l}\text { 2. Dealing with needs } \\
\text { Parents' sensitivity to daughters' feelings and needs }\end{array}$} \\
\hline Childhood & 3.92 & 0.95 & 4.05 & 0.88 & $-0.96(184)$ & 3.49 & 0.97 & 3.63 & 0.93 & $-1.00(184)$ \\
\hline Adolescence & 3.34 & 1.09 & 3.74 & 0.92 & $-2.68(184)^{* *}$ & 2.96 & 0.95 & 3.37 & 0.95 & $-2.92(184)^{* * *}$ \\
\hline $\begin{array}{c}\text { Childhood-adolescence } \\
t(d f) \\
\end{array}$ & \multicolumn{2}{|c|}{$5.41(92)^{* * *}$} & \multicolumn{3}{|c|}{$4.17(92)^{* * *}$} & \multicolumn{2}{|c|}{$5.00(92)^{* * *}$} & \multicolumn{3}{|c|}{$3.01(92)^{* *}$} \\
\hline \multicolumn{11}{|c|}{-Parents' support of daughters' feelings and needs } \\
\hline Childhood & 4.42 & 0.73 & 4.40 & 0.65 & $0.21(184)$ & 4.01 & 0.87 & 4.17 & 0.85 & $-1.28(184)$ \\
\hline Adolescence & 3.83 & 0.92 & 4.08 & 0.78 & $-1.98(184)^{*}$ & 3.49 & 0.92 & 3.85 & 1.05 & $-2.45(184)^{*}$ \\
\hline $\begin{array}{c}\text { Childhood-adolescence } \\
t(d f) \\
\end{array}$ & \multicolumn{2}{|c|}{$6.92(92)^{* * *}$} & \multicolumn{3}{|c|}{$4.59(92)^{* * *}$} & \multicolumn{2}{|c|}{$5.74(92)^{* * *}$} & \multicolumn{3}{|c|}{$3.72(92)^{* * *}$} \\
\hline \multicolumn{11}{|c|}{ Closeness between parents and daughter } \\
\hline Childhood & 4.12 & 1.02 & 4.53 & 0.73 & $-3.18(167)^{* *}$ & 3.86 & 1.06 & 4.20 & 0.93 & $-2.36(184)^{*}$ \\
\hline Adolescence & 3.56 & 1.16 & 4.07 & 0.90 & $-3.32(183)^{* *}$ & 3.09 & 1.03 & 3.78 & 1.03 & $-2.63(184)^{* *}$ \\
\hline $\begin{array}{c}\text { Childhood-adolescence } \\
t(d f)\end{array}$ & \multicolumn{2}{|c|}{$4.55(92)^{* * *}$} & \multicolumn{3}{|c|}{$5.67(92)^{* * *}$} & \multicolumn{2}{|c|}{$6.27(92)^{* * *}$} & \multicolumn{3}{|c|}{$4.49(92)^{* * *}$} \\
\hline \multicolumn{11}{|c|}{-Parents' happiness with parental role } \\
\hline Childhood & 3.95 & 0.99 & 3.83 & 0.85 & $0.87(184)$ & 4.08 & 0.89 & 3.54 & 0.85 & $4.19(183)^{* * *}$ \\
\hline Adolescence & 3.72 & 0.99 & 3.59 & 0.91 & $0.92(184)$ & 3.60 & 0.90 & 3.28 & 0.88 & $2.43(183)^{*}$ \\
\hline $\begin{array}{c}\text { Childhood-adolescence } \\
t(d f) \\
\end{array}$ & \multicolumn{2}{|c|}{$2.25(92)^{*}$} & \multicolumn{3}{|c|}{$2.76(92)^{* *}$} & & $2)^{* * *}$ & & 2.86 & $(92)^{* * *}$ \\
\hline 3. Parents' intrusiveness & & & & & & & & & & \\
\hline Childhood & 3.80 & 1.11 & 4.10 & 0.93 & $-2.00(184)^{*}$ & 4.30 & 0.82 & 4.32 & 0.92 & $-0.17(184)$ \\
\hline Adolescence & 3.58 & 1.12 & \begin{tabular}{l|l}
4.03 \\
\end{tabular} & 0.94 & $-2.99(178)^{*}$ & 3.90 & 1.09 & \begin{tabular}{|l|l|}
4.24 \\
\end{tabular} & 1.04 & $-2.13(184)^{*}$ \\
\hline $\begin{array}{c}\text { Childhood-adolescence } \\
t(d f) \\
\end{array}$ & 2.1 & & & & $0(92)$ & & $2)^{* * *}$ & & & $7(92)$ \\
\hline
\end{tabular}

Notes. ${ }^{*} p<0.05 ;{ }^{* *} p<0.01 ;{ }^{* * *} p<0.001$. 
Where the family members answered questions about important qualities of parenting, significant differences in perception were apparent in the period of childhood in three out of six variables and in the period of adolescence in five out of six variables (see Table 1). As far as significant differences are concerned, daughters are consistently more critical in their perceptions of family interactions than either parent. Only with the variables concerning the parents' happiness with the parental role and the parents' anxiety about parenting are the results inverted. Fathers rate happiness with their parental role significantly lower than that perceived by daughters. It is obvious that daughters do not recognize the father's dissatisfaction with his parental role. No significant differences on this variable were found when it came to mothers and daughters.

While examining whether or not individual family members perceive their interactions with each other differently during the period of the daughter's childhood and her adolescence, there were significant differences in five (out of six) variables, with the variable concerning the parents' anxiety about parenting being the exception. Therefore, the differences in experiencing the qualities of parenting between a daughter and her parents increase in adolescence. All family members experienced a drop in the quality of interaction during adolescence, which is consistent with the findings of other researchers (Paulson \& Sputa, 1996).

For exploring the differences among the family members according to perceiving family competence, we used the one-way ANOVA (analysis of variance). Here, we analyze only the last two composite variables of the second part of the questionnaire (communication and dealing with emotions) (see Table 2). As with the $t$-test, the Levene statistic for testing the homogeneity of variances was considered in advance.

Table 2

Differences Among the Family Members According to Experiencing Communication and Dealing With Emotions in the Family System

\begin{tabular}{|l|c|c|c|c|c|c|c|}
\hline Variable/subject & \multicolumn{2}{|c|}{ Adolescent perceived } & \multicolumn{2}{|c|}{ Mother perceived } & \multicolumn{2}{|c|}{ Father perceived } & \multirow{2}{*}{$F(d f)$} \\
\hline & $M$ & $S D$ & $M$ & $S D$ & $M$ & $S D$ & \\
\hline $\begin{array}{l}\text { 1.Communication } \\
\text { (composite variable) }\end{array}$ & 13.45 & 2.94 & 14.91 & 2.30 & 15.21 & 2.39 & $12.63(276)^{* * *}$ \\
\hline -Negotiation & 3.28 & 0.98 & 3.72 & 0.88 & 3.85 & 0.85 & $10.17(279)^{* * *}$ \\
\hline -Communication & 3.42 & 0.92 & 3.89 & 0.70 & 3.91 & 0.70 & $11.88(279)^{* * *}$ \\
\hline -Dealing with conflicts & 2.94 & 1.08 & 3.48 & 0.94 & 3.55 & 0.94 & $10.79(2)^{* * *}$ \\
\hline -Connecting to surroundings & 3.82 & 0.87 & 3.82 & 0.71 & 3.90 & 0.81 & $0.36(2)$ \\
\hline $\begin{array}{l}\text { 2. Dealing with emotions } \\
\text { (composite variable) }\end{array}$ & 14.85 & 3.16 & 16.01 & 2.52 & 15.72 & 2.44 & $4.55(275)^{* *}$ \\
\hline -Permeability & 3.34 & 0.99 & 3.82 & 0.72 & 3.89 & 0.68 & $12.48(276)^{* * *}$ \\
\hline -Expressiveness & 3.67 & 0.92 & 3.96 & 0.90 & 3.71 & 0.89 & $2.79(2)$ \\
\hline -Mood and tone & 3.96 & 0.95 & 4.01 & 0.77 & 4.08 & 0.77 & $0.47(276)$ \\
\hline -Empathy & 3.88 & 1.00 & 4.23 & 0.86 & 4.04 & 0.82 & $3.43(275)^{* *}$ \\
\hline
\end{tabular}

Notes. ${ }^{*} p<0.05 ;{ }^{* *} p<0.01 ;{ }^{* * *} p<0.001$.

The perception of communication within the family in general terms (taking into account all of the variables for the composite variable) differs with all three family members, as indicated by post hoc analyses (Scheffe test). Significant differences also appear between the way the daughter and the mother experience dealing with emotions within the family (taking into account all of the variables concerning emotions).

As with experiencing the quality of parenting, the individual's perception of family competence is consistently assessed higher by the parents than by the daughters. In the majority of cases, the assessments 
given by fathers were the highest. Only in two individual variables (expressiveness and empathy) did mothers assess interaction the best.

Daughters perceive interactions differently than their parents. This is one of the main findings of the research; of all of the family members, the evaluations of the daughters were the most critical (lower than the parents' evaluations). Similar findings have been recorded in other research (Adams, 1985; Dekovic, Noom, \& Meeus, 1997; Paulson \& Sputa, 1996).

\section{Family Competence and the Psychosocial Development of Family Members}

Beavers' competence model, which represents the starting point for examining the family in this research, defines competence in terms of the structure of the family unit and the interactions within it (Beavers \& Hampson, 1993). It has proven to be a useful model for examining the family's role in the development of the female adolescent. For this purpose, we analysed the variables of Part 2 of the "Family of Origin Questionnaire", which concerns questions about family competence. In consistence with Fisher and Ransom (1995), we used cluster analysis, which turned out to be the most useful method for examining the perception of family competence. As we consider the family as a unit, in the analysis, we compute all of the variables of the questionnaire concerning experiencing the family as a system (see the section on measuring tools), i.e., ten variables for each of the family members (30 in total). We used Ward's method (Norušis, 1994) method and the squared Euclidean distance measure. Our expectation was that families would be classified according to family competence and this expectation was confirmed. The two cluster solution proved to be the best. In each of the clusters, exactly half of the families $(N=46)$ were grouped.

Table 3

Means of Family Competence for Family Members in Less and More Competent Families

\begin{tabular}{|c|c|c|c|c|c|c|}
\hline \multirow[b]{2}{*}{ Family competence } & \multicolumn{2}{|c|}{ Adolescent } & \multicolumn{2}{|c|}{ Mother } & \multicolumn{2}{|c|}{ Father } \\
\hline & Less & More & Less & More & Less & More \\
\hline \multicolumn{7}{|l|}{ 1. Structure } \\
\hline Decision-making & 3.83 & 4.57 & 4.09 & 4.74 & 4.09 & 4.74 \\
\hline Parental coalition & 3.43 & 4.02 & 3.30 & 4.17 & 3.39 & 4.09 \\
\hline \multicolumn{7}{|l|}{ 2. Communication } \\
\hline Negotiation & 2.78 & 3.76 & 3.30 & 4.13 & 3.43 & 4.26 \\
\hline Communication & 3.02 & 3.80 & 3.56 & 4.22 & 3.54 & 4.28 \\
\hline Conflict & 2.48 & 3.41 & 3.11 & 3.87 & 3.33 & 3.76 \\
\hline Connecting to surr. & 3.57 & 4.07 & 3.67 & 3.97 & 3.61 & 4.20 \\
\hline \multicolumn{7}{|c|}{ 3. Dealing with emotions } \\
\hline Permeability & 2.08 & 3.87 & 3.43 & 4.20 & 3.50 & 4.28 \\
\hline Expressiveness & 3.22 & 4.13 & 3.54 & 4.39 & 3.35 & 4.09 \\
\hline Mood and tone & 3.34 & 4.67 & 3.63 & 4.39 & 3.63 & 4.52 \\
\hline Empathy & 3.43 & 4.30 & 3.87 & 4.59 & 3.85 & 4.23 \\
\hline
\end{tabular}

In terms of perceiving family interaction, the families separated themselves clearly on the competence continuum into two equally sized groups: into less and more competent families (see Table 3). The means of all of the variables for all of the family members are, as a rule, divided into two groups. All of the means for the first (less competent) group are under the grouped means and all of the means for the second (more competent) group are above them. The cluster membership was saved for the families (cases) for further analysis.

We found significant, albeit not very high correlations between the family's competence and the level of 
the adolescent's psychosocial development, as well as the parents' psychosocial development (Pearson $r$ (adolescent) $=0.36^{* *} ; r$ (mother) $=0.34^{* *} ; r$ (father) $\left.=0.32^{* *}\right)$. Lewis (1989) stated that a competent family enables the development not only of the children but also of the parents. We assume that higher psychosocial development enables parents to create more competent relationships in the families which also enable favourable development in adolescents. The results have also indicated a stronger significant correlation between the degree of the daughter's and the mother's psychosocial development $\left(r=0.31^{* *}\right)$ than between that of the daughter and the father $\left(r=0.23^{*}\right)$. D. C. Bell and L. G. Bell (1983) also found that an adolescent daughter's self-regard and self-awareness are positively related to the mother's support and validation respectively, but not to the father's.

\section{Discussion}

One of the main findings of the research is that daughters and their parents perceive the interactions in the family system differently. The daughters' evaluations were the lowest, i.e., the most critical. Similar findings have been recorded by other researchers (Adams, 1985; Dekovic et al., 1997; Paulson \& Sputa, 1996). Paulson and Sputa (1996) cited that parents reported themselves to have higher levels of involvement in parenting than did their adolescents. Dekovic et al. (1997) claimed that these differences in perception are larger in families where there are more conflicts between the adolescents and the parents, usually concerning the different expectations they have regarding the adolescents' autonomy. In our study, there are probably no differences between the parents because of the necessary generational differences in a family structure (Poljšak Škraban, 2002b). Smrtnik Vitulić and Zupančič (2009) found that ratings are always subjectively biased and parents share a similar role perspective and have similar expectations, norms and values with regard to family functioning. Noller and Callan (1991) established that the evaluation given by adolescents is more "objective" than that given by parents and usually corresponds to the assessment of experts.

This fact begs the question as to whether there is such a thing as an objective fact when it comes to families. It is our claim that an individual's perception, the way one experiences things, is vital, because it significantly defines an individual and his/her perspective. Adams (1999; as cited in Hofer, Chasiotis, Kiessling, \& Busch, 2006) concluded that moderate levels of conflict in combination with an acceptance of the different views of family members, particularly conflictive views of parents and adolescents, encourage the development of psychosocially advanced identity statuses. Our results confirm the thesis of many authors who claim that the period of adolescence is the hardest test for the quality of the relationship between the parents and within the family as a whole. Nielsen (1996) added that for adolescents arguing with parents is actually a necessary part of becoming self-reliant and developing an identity. Although we agree, we have to emphasize that too many differences in experiencing interpersonal interaction within the family often lead to conflict. The conflicts caused by the adolescent compel the family (particularly the parents) to change something that cannot be achieved without adequate communication. The family should be able to repeatedly establish mutual and open communication, thus making it possible to strike a balance between the autonomy and the interconnectedness of family members. In principle, only a competent family is able to do this.

Lewis (1989) asserted that a competent family is one that provides the (male or female) adolescent with the optimal conditions for developing his/her identity. Powers, Hauser, Schwartz, Noam, and Jacobson (1983) and Allen, Hauser, Bell, and O'Connor (1994) also found that the amount of supportive interaction in the family proved to be a very good predictor of adolescent ego development. Our results, showing that 
psychosocial development of family members correlated with the family competence, can also be understood in this manner.

\section{Conclusions and Implications in Practice}

Naturally, the results of the research cannot be generalized and cannot be applied to the entire population. After all, modern society is so diverse that it is important to conduct research within a carefully selected context (Petzold, 1996), which in turn sheds light on merely a small part of a very complex field. There are, of course, some findings that are very useful for working with adolescents in schools and with the families of adolescents.

In our research, we have focused only on nuclear (two-parent) families. However, we think that the results of the research can to some extent be applied to different family structures (e.g., a single parent family or in a reconstituted family). McGurk and Soriano (1998; as cited in Beveridge, 2005) concluded that what is most significant for children's development is the quality of the care they receive rather than the particular family structure. Thus, in any type of family structure, the adolescent should experience the feelings referred to by Kempler (1975; as cited in Čačinovič Vogrinčič, 1995, p. 122),

A happy family is one where the home is formed according to the reality of those who dwell in it, and not according to what a home should look like and how a family should behave. The adolescent needs the home to change, but the home is shared with others and therefore all family members take part in altering it.

This is exactly what happens in a competent family. Čačinovič Vogrinčič $(1995$, p. 125) described it as follows:

...boundaries constantly need to be re-established; sometimes they need to be demanded, other times negotiated.... We both learn. The adolescent learns to act according to his new competence levels, and we as parents learn what it is they need from us, what they wish to alter. As parents, we learn to change the rules as well as the roles; we learn to accept the new degrees of the adolescent's autonomy and competence. And in doing so, we require each other's help.

The finding that parents perceived themselves to have higher levels of interaction in the family than did their adolescents shows that it is important for parents to understand that although they may perceive their interaction to be at one level, adolescents may not perceive their behaviour and feelings in the same way. Practitioners need to be aware of the implications of these findings when they are reported as a single respondent's perceptions (i.e., one parent and not the adolescent, or the adolescent and neither parent). Although it may never be clear whose perceptions (parents' or adolescents') more accurately reflect the actual level of family functioning in the home, it may be the perceptions themselves that are more important for predicting outcomes than the actual behaviour. D. C. Bell and L. G. Bell (1983) stressed that the accuracy of interpersonal perception enhances an individual's ability to carry on a mutually validating relationship and communicate. In their research, they found a strong direct effect of the accuracy of interpersonal perception on adolescent ego development. Misinterpretation of another's behaviour may be a primary source of conflict in families with adolescents. Salmon and Shackelford (2007) emphasized the role of understanding the psychology of family dynamics in understanding not only the parents' but also the children's behaviour. However, we must also pay attention to the fact that, from a family system perspective, although analysis of ongoing family interaction provides information about the level of support or comfort with disagreement within the family, it says less about the attitudes and values of individual family members. Nonetheless, many paths connect family system processes and the individual development of family members. Walsh (1993) also 
stressed the importance of respecting individual differences, autonomy, an individual's needs and of encouraging the fostering of the family members' well being, regardless of which generation they belong to. These facts are the basis for working with adolescents and their families. The role of the counsellor, as Čačinovič Vogrinčič (1995) saw it, is also in collaborating when it comes to discerning, explaining and naming every single element of very concrete situations in terms of these major themes-just authority, new competence of the young person, negotiation over changing rules, accepting the adolescent's assistance and negotiating new but clear boundaries.

\section{References}

Adams, G. R. (1985). Family correlates of female adolescents' ego-development. Journal of Adolescence, 8, 69-82.

Adams, G. R., \& Marshall, S. K. (1996). A developmental social psychology of identity: Understanding the person-in-context. Journal of Adolescence, 19, 249-256.

Allen, J. P., Hauser, S. T., Bell, K. L., \& O'Connor, T. G. (1994). Longitudinal assessment of autonomy and relatedness in adolescent-family interactions as predictors of adolescent ego development. Child Development, 65, 179-194.

Bartle-Haring, S. (1997). The relationship among parent-differentiation, sex role orientation and identity development in late adolescence and early adulthood. Journal of Adolescence, 20, 553-565.

Beavers, W. R. (1976). Theoretical basis for family evaluation. In J. M. Lewis, W. R. Beavers, J. T. Gossett, \& O. Philips (Eds.), No single thread (pp. 46-82). New York: Brunner/Mazel Publishers.

Beavers, W. R., \& Hampson, R. B. (1993). Measuring family competence: The Beavers systems model. In F. Walsh (Ed.), Normal family processes (pp. 73-103). London: The Guilford Press.

Beavers, W. R., \& Hampson, R. B. (2000). The Beavers systems model of family functioning. Journal of Family Therapy, 22, 128-143.

Bell, D. C., \& Bell, L. G. (1983). Parental validation and support in the development of adolescent daughters. In H. D. Grotevant, \& C. R. Cooper (Eds.), Adolescent development in the family: New directions for child development (pp. 27-42). San Francisco: Jossey-Bass Inc. Publishers.

Beveridge, S. (2005). Children, families and schools: Developing partnerships for inclusive education. London: Routledge Falmer.

Beyers, W., \& Goosens, L. (2008). Dynamics of perceived parenting and identity formation in late adolescence. Journal of Adolescence, 31(2), 165-184.

Bradley, C. L. (1985). A study of the stability and validity of the generativity status measure in adulthood (Doctoral dissertation, Simon Fraser University).

Čačinovič Vogrinčič, G. (1995). Adolescent in the family. In V. Velikonja, J. Grgurevič, \& B. Žemva (Eds.), Experimental psychotherapy within families - Theory and praxis in Slovenia (pp. 17-24). Ljubljana: Quatro d.o.o..

Čačinovič Vogrinčič, G. (1998). Family psychology. Ljubljana: Znanstveno in publicistično središče.

Cooper, C. R., \& Grotevant, H. D. (1987). Gender issues in the interface of family experience and adolescents' friendship and dating identity. Journal of Youth and Adolescence, 16(3), 247-264.

Dekovic, M., Noom, M. J., \& Meeus, W. (1997). Expectations regarding development during adolescence: Parental and adolescent perceptions. Journal of Youth and Adolescence, 26, 253-266.

Erikson, E. H. (1968). Identity: Youth and crisis. New York: Norton.

Erikson, E. H. (1980). Identity and the life cycle. New York: W. W. Norton \& Company.

Fisher, L., \& Ransom, D. C. (1995). An empirically derived typology of families: I. relationships with adult-health. Family Process, 34, 161-182.

Fisher, L., Kokes, R. F., Ransom, D. C., Phillips, S. L., \& Rudd, P. (1985). Alternative strategies for creating "relational" family data. Family Process, 24, 213-224.

Gilligan, C. (1982). In a different voice. Cambridge: Harvard University Press.

Grotevant, H. D., \& Cooper, C. R. (1985). Patterns of interaction in family relationships and the development of identity exploration in adolescence. Child Development, 56, 415-428.

Hofer, J., Chasiotis, A., Kiessling, F., \& Busch, H. (2006). Quality of familial relations in childhood and ego identity formation: The moderating influence of dispositions of action control. In Identity: An International Journal of Theory and Research, 6(2), 117-140. 
Josselson, R. (1987). Finding herself. San Francisco: Jossey-Bass Publishers.

Kroger, J. (2004). Identity in adolescence: The balance between self and other. London, New York: Routledge.

Lamovec, T. (1994). Psychodiagnostic of personality 2. Ljubljana: Filozofska fakulteta, Znanstveni inštitut filozofske fakultete.

Lewis, J. M. (1989). The birth of the family: An empirical inquiry. New York: Brunner/Mazel, Inc..

Marcia, J. E. (1993). The status of the statuses: Research review. In J. E. Marcia, A. S. Waterman, D. R. Matteson, S. L. Archer, \& J. L. Orlofsky (Eds.), Ego identity (pp. 22-41). New York: Springer-Verlag.

Nielsen, L. (1996). Adolescence: A contemporary view. New York: Holt, Rinehart and Winston, Inc..

Norušis, M. J. (1994). SPSS professional statistics 6.1. USA: SPSS Inc..

Noller, P., \& Callan, V. (1991). The adolescent in the family. London: Routledge.

Ochse, R., \& Plug, C. (1986). Cross-cultural investigation of the validity of Erikson's theory of personality development. Journal of Personality and Social Psychology, 6, 1240-1252.

Paulson, S. E., \& Sputa, C. L. (1996). Patterns of parenting during adolescence: Perceptions of adolescents and parents. Adolescence, 31, 369-381.

Petzold, M. (1996). The psychological definition of "the family". In M. Cusinato (Ed.), Research on family resources and needs across the world (pp. 25-44). Milano: LED.

Poljšak Škraban, O. (2002a). The role of parents and interactions within the family system at forming the identity of the female students of social pedagogy (Unpublished doctoral dissertation, University of Ljubljana).

Poljšak Škraban, O. (2002b). An adolescent in the family and the interpersonal experience of family members. Socialna Pedagogika, 6(4), 369-394.

Powers, S. I., Hauser, S. T., Schwartz, J. M., Noam, G. G., \& Jacobson, A. M. (1983). Adolescent ego development and family interaction: A structural-developmental perspective. In H. D. Grotevant, \& C. R. Cooper (Eds.), Adolescent development in the family (pp. 5-25). San Francisco: Jossey-Bass Publishers.

Salmon, C. A., \& Shackelford, T. K. (2007). Family relationships: An evolutionary perspective. New York: Oxford University Press.

Smrtnik Vitulić, H., \& Zupančič, M. (2009). Agreement between different groups of informants reporting on adolescents' personality. Didactica Slovenica-Pedagoška obzorja, 24(3-4), 87-103.

Ule, M. (2008). Forever young? Social psychology of growing up. Ljubljana: Faculty of Social Sciences \& Littera picta.

Walsh, F. (1993). Conceptualization of normal family processes. In F. Walsh (Ed.), Normal family processes (pp. 3-69). London: The Guilford Press. 